\title{
Partidas e retornos na literatura de Ferreira de Castro
}

\author{
Vander da Conceição Madeira ${ }^{1}$
}

RESUMO: Analisamos neste artigo como Ferreira de Castro aborda o tema da emigração para as Américas em três de seus romances. Emigrantes (1928), A selva (1930) e Terra fria (1933) abordam a partida e retorno dos portugueses, refletindo sobre as causas da emigração e seus efeitos sobre homens e comunidades.

ABSTRACT: This article analyzes how Ferreira de Castro deals with the theme of emigration to America on three of his novels. Emigrantes (1928), A selva (1930) and Terra fria (1933) deal with the departure and arrival of Portuguese, also thinking about the causes of emigration and its effect on men and communities.

PALAVRAS-CHAVE: Emigração; Estrangeiro; Ferreira de Castro KEYWORDS: Emigration; Foreign; Ferreira de Castro

\section{Partidas e retornos}

A imagem do épico, do ousado aventureiro que enfrenta o desconhecido e conquista o mundo, não predominou na literatura portuguesa. No século XIX a partida se nos apresenta de forma distinta. No lugar do heroico conquistador encontramos quase a sua antítese. É o homem derrotado pela miséria, sem perspectiva de trabalho, que se vê obrigado a cruzar o Atlântico. O herói tornou-se o emigrante que parte em busca de uma riqueza tão incerta quanto a sua volta.

Se a partida é carregada de sentimentalismo e tristeza, a volta não corresponderá ao júbilo e alegria na medida inversa. "O trabalho

1 Doutorando em Estudos Comparados de Literaturas de Lingua Portuguesa, FFLCH/USP. Contato: vandermadeira@usp.br 
despoetiza o triste emigrante" (QUEIRÓS, s. d., p. 20) e o viajante que faz o caminho de volta à sua aldeia já é visto com um "outro" que a ficção portuguesa vai destacar, em vários momentos, como um tipo muito particular, o "brasileiro". O português que retorna rico depois de emigrar torna-se objeto de curiosidade, inveja, admiração e desprezo dos conterrâneos. Autores do século XIX apresentam o "brasileiro" como um somatório de defeitos: "Já engonçado, já enfardelado, com todos os seus joanetes e todos os seus diamantes, crasso, glutão, manhoso, e revelando placidamente na linguagem mais bronca os sentimentos mais sórdidos” (QUEIRÓS, s. d., p. 19).

No século XX, Ferreira de Castro é um dos autores em cuja ficção encontramos o famigerado personagem. Entre os quatro romances de Castro publicados no período de 1928 a 1933, Emigrantes (1928), A selva (1930), Eternidade (1933) e Terra Fria (1933), apenas Eternidade não conta com a presença de um emigrante português que retorna da América. Como se percebe, os temas da partida e do retorno são caros ao autor, personagem real de um momento histórico em que a partida para a América do Sul ou do Norte pareceu ser a oportunidade de escapar da miséria reinante nas pequenas aldeias lusitanas. A selva, maior êxito literário de Ferreira de Castro, deve muito de sua força à experiência vivida pelo autor como trabalhador de seringal na Amazônia.

\section{Emigrantes}

Primeiro romance de Ferreira de Castro depois de seu retorno a Portugal, Emigrantes conta a história de Manuel da Bouça, um camponês pobre e analfabeto que, já em idade madura e com família constituída, é seduzido pelo sonho de enriquecer emigrando para o Brasil. O romance mostra o percurso completo do candidato a "brasileiro", o surgimento do desejo de emigrar, os indutores de tal desejo, as dificuldades para conseguir sair de Portugal, a realidade do trabalho no Brasil e o retorno de Manuel à sua aldeia. 
Manuel da Bouça arrisca os poucos bens da família, pois para seguir viagem seria necessário hipotecar sua pequena propriedade.

O oiro do Brasil fazia parte da tradição e tinha o prestígio duma lenda entre os espíritos rudes e simples. [...] Palavra mágica, o Brasil exercia ali um perene sortilégio e só a sua evocação era motivo de visões esplendorosas, de opulências deslumbrantes e vidas liberadas. (CASTRO, 1959, p. 298)

As poucas perspectivas econômicas locais, a vontade de progredir, a ilusão e a ignorância de tipos como Manuel eram garantia de ganhos para homens como Carrazedas, a quem hipotecou seu patrimônio e Nunes, dono da agência que preparava os documentos para a viagem. Para eles, exportar mão de obra era uma atividade lucrativa.

Nunes utiliza o jornal local para divulgar informações fantasiosas sobre as oportunidades de trabalho fora de Portugal, como se percebe de sua conversa com o jornalista Borges, a quem encomenda uma nota sobre seus negócios e uma "notícia" sobre oportunidades de trabalho para quem emigra:

- [...] Mas, como eu ia dizendo, o que eu queria era que o Borges escrevesse, antes da notícia da inauguração da agencia, uma outra sobre a emigração para a América do Norte... Mais ou menos o seguinte: sabemos que na América do Norte há grande falta de braços e que todas as pessoas que para ali emigram encontram fácil colocação e ganham rios de dinheiro. (CASTRO, p. 318)

Como a anunciar o fim do sonho, a viagem de Manuel para o Brasil é feita em um apinhado "Navio de emigrantes" bastante semelhante ao pintado por Lasar Segall. Já em terra, ao encontrar Cipriano, o conterrâneo que imaginava bem estabelecido e rico, tem o primeiro contato com a realidade que o espera.

- Porque aqui, como em todo o mundo, as coisas vão mal. Quase não se ganha para viver.[...] todos nós mandamos dizer que estamos aqui muito bem, que é para a nossa família não se afligir e para não fazermos má figura junto dos conhecidos... (CASTRO, p. 379-380) 
Sem opções, o recém-chegado vê-se obrigado a integrar o "rebanho" dos que se destinam à lavoura.

Passada a fase de trabalho na fazenda, Manuel retorna à capital paulista onde consegue emprego na mesma mercearia que Cipriano.

As notícias de casa aumentam o sofrimento de Manuel: um dia é filha que foge para casar-se, depois a esposa doente e, finalmente, a execução da hipoteca. Nove anos no Brasil e o imigrante tem apenas o necessário para não morrer de fome e a amargura da derrota.

A morte da esposa dá a Manuel a certeza da inutilidade de tudo que fizera nos últimos anos. Sendo assim, para que voltar a Portugal? A ideia inicial de nunca mais retornar é pouco a pouco substituída pela saudade:

A terra em que nascera fazia-se lembrar agora de maneira diferente, como se a própria evocação tivesse sabor - um amargo sabor de tristeza. Mas continuava a seduzi-lo, a fascinálo de longe, contrariando decisões de horas antes. "Gostaria de ver o lugar onde tinham enterrado a sua Amélia e de comprar, se pudesse, a sua sepultura. Gostaria de ver... Gostaria de ver..." (CASTRO, p. 463)

O cândido personagem do início quase não existe mais e no lugar do sonho dourado instalara-se uma certeza: "para os pobres, todo o mundo era mau..." (CASTRO, p. 463). Tal pensamento e uma réstia da ingenuidade original dão ao português a coragem para sair às ruas durante uma revolta operária em São Paulo e o fazem crer no discurso revolucionário do amigo Hermenegildo:

Ser português, ser italiano ou ser cá do Brasil, isso não tem importância. O que vale é ser proletário, é ser um homem. Nós somos todos irmãos. Os outros é que não são. Eles tiramnos a pele em toda a parte do mundo, sem perguntar onde cada um nasceu. (CASTRO, p. 471)

A amargura e a pregação revolucionária são insuficientes para fazer com que o camponês da Bouça atire em um adversário legalista, mas a breve participação na revolta muda a sorte de Manuel. Recuando 
para voltar à pensão onde morava ele tropeça em um cadáver. Ao choque do encontro com o corpo seguiu-se a angústia de aproveitar a oportunidade que surgia, pois o morto portava anéis e corrente com relógio.

A possibilidade de imediato regresso ia-se tornando mais nítida, cada vez mais nítida e alvoroçante. E era já fogo interior, a subir, a abrasá-lo. "Para quê ficar mais tempo? Para quê? Para trabalhar sem nenhum futuro? Se ele fizesse aquilo, quem o saberia?" [...] // Hesitou ainda: venceu-se e largou de ali. Depois, voltou-se e, numa súbita imposição correu para o cadáver, ajoelhou-se, fechou os olhos e agarrou-lhe as mãos, para logo as abandonar, ao sentir nas suas o sangue que as encharcava. Refez-se e nervoso, apressado, volveu à tarefa, tirando os aneis e puxando pela corrente, que trouxe, dependurado, um relógio. Sem nada ver, guardou tudo no bolso e ergueu-se rapidamente. (CASTRO, p. 476-477)

Se o ímpeto revolucionário do imigrante não durou um dia, o medo de ser preso pela aventura perseguiu Manuel mesmo depois de abandonar a pensão e se esconder com os amigos revoltosos.

No cais, esperando o momento de embarcar de volta a Portugal, Manuel da Bouça observa aqueles que chegam do exterior:

[...] haviam chegado outros, assim, na véspera; há já muitas dezenas de anos que a cena se repetia - um cortejo interminável de famintos, que a Europa fabricava mas não alimentava, a não ser quando carecia do corpo deles para alvo de canhões. E era sempre sombrio o bando que descia; por mais garridas e policromas que fossem as vestes das mulheres, 0 conjunto dava sempre uma triste sugestão de negrume e de fome. (CASTRO, p. 489)

Uma vez embarcado, o personagem já sente saudades da terra onde sofrera tanto. A tristeza do momento contrasta com a alegria imaginada para a hora da partida. Manuel da Bouça tinha por companhia muitos que, como ele, emigraram em busca de uma riqueza que nunca alcançaram. A dezena de vencedores viajava na primeira classe, distantes do "carregamento de carne humana, exausta, quase morta, que a América devolvia à Europa" (CASTRO, p. 493). 
O caminho de volta para casa motiva recordações, e entre elas está a condição em que partira. E Manuel da Bouça recusa-se a confessar sua derrota.

Apesar de reconhecer na estrada o pinheiro onde brincava na infância, Manuel se perturba ao perceber que muito do que vê não existia antes. "Como tudo está mudado! Ir ao Brasil era como se um homem morresse e ressuscitasse muito tempo depois." (CASTRO, p. 499) Para quem o vê, Manuel também está mudado, parece ter realizado o sonho de riqueza além-mar.

Parado à porta da casa onde vivera, com sua mala de "brasileiro" a anunciar que vinha de longe, relembra seu passado, contabiliza e chora suas perdas.

[...] casa vazia, desabitada, onde já não existia o seu amor de outrora, onde desaparecera, durante sua ausência, o carinho da sua vida. [...] Por toda parte, no couval, no muro, na vinha, a desolação falava dele, que partira, e de Amélia, que morrera. (CASTRO, p. 500)

O encontro com os velhos amigos tem a sombra do fracasso, pois eles o saúdam e louvam-lhe a fortuna amealhada.

Sentia que a verdade quebraria a vitória daquele momento, lançando no ambiente de adulação um silêncio incômodo amesquinhando-o, envergonhando-o. Súbita cobardia amarravao à mentira, perante os olhos ávidos dos vizinhos, daqueles velhos conhecidos, que o desprezariam se conhecessem a realidade. (CASTRO, p. 503)

A recepção era como sonhara quando partira, era fruto da ilusão partilhada. E como os sonhos daquele tempo, era sustentada por uma mentira. Na verdade, a riqueza estava do outro lado, na iluminada casa do Nunes, a única da freguesia a contar com luz elétrica.

Como a ilusão de uma vida não se apaga tão facilmente, Manuel logo sai à procura de Zé do Aido, um conterrâneo que arriscara a sorte na América do Norte. O "brasileiro" tem certeza de que o outro fizera a opção correta e partira para onde a riqueza estava à espera dos 
emigrantes. Em mais um encontro com a realidade, Manuel ouve de Aido as agruras da aventura e fica sabendo que também no Norte "Havia muito dinheiro, sim, senhor, mas era de quem o tinha" (CASTRO, p. 510). A derrocada de Zé do Aido incomoda menos do que a suposição de que ele havia triunfado nos Estados Unidos. E com seu fato novo, Manuel, supostamente agraciado pela sorte, "cada vez mais humilhado, mais triste" (CASTRO, p. 511), retorna à casa a pensar: "Raio de vida! Mas então se não é na América, onde era a terra em que os pobres podiam levantar a cabeça?" (CASTRO, p. 511)

Depois de nove anos longe do campo, a possibilidade de voltar à enxada lhe parece impossível:

Sentia algo que não sabia explicar a si próprio, mas que o divorciava da terra; algo que se intrometera no seu espírito enquanto estivera longe, fazendo dele um homem diferente do que era antes de ir para o Brasil. Sentia-se quase um estranho ali e via tudo com olhos de quem não vem pra ficar, de quem já não é capaz de ficar sem grande sacrificio. (CASTRO, p. 513)

Derrotado em todas as suas expectativas, um estranho na própria terra e sabedor de que a farsa não duraria para sempre, Manuel parte novamente.

Não levava já a ânsia de volver, como há nove anos, quando partira para o Brasil; desejava apenas ocultar em Lisboa a sua miséria e que nunca mais se lembrassem dele, que o esquecessem para sempre. (CASTRO, p. 523)

$\mathrm{Na}$ estrada, tem vontade "de chorar a sua vida inutilizada, o passado que não voltaria, as ilusões que fora abandonando ao longo da áspera jornada" (CASTRO, p. 524).

Às costas de Manuel fica o palacete do Nunes, imponente em meio à simplicidade do entorno.

\section{A selva}


O segundo romance de Ferreira de Castro conta o drama de Alberto, jovem estudante português que, obrigado a emigrar, acaba por empregar-se em um seringal na região amazônica. Repleto de traços autobiográficos, o romance focaliza simultaneamente a adaptação do emigrante à sua condição de estrangeiro e seringueiro e a realidade dos trabalhadores engajados na extração do látex na selva. Elaborado como denúncia do processo de escravização dos seringueiros, o romance mostra como o sonho de enriquecimento "fácil" levou milhares de homens a confrontar os riscos da vida na floresta e fez a riqueza de uns poucos comerciantes e patrões.

Temos em A selva o percurso de transformação do personagem Alberto. Obrigado a emigrar em função de sua participação em uma revolta monarquista, o estudante de direito nada tem em comum com os milhares de emigrantes que deixavam Portugal para fugir da pobreza e com a expectativa de enriquecer no Brasil. A crença em sua condição de homem superior não o havia preparado para a vida dura de trabalhador braçal, mas o destino o leva à condição de humilde empregado de seringal. É na floresta que Alberto percebe a inutilidade de seus preconceitos de classe e descobre que de nada valem sua cultura, orgulho e ares elegantes em um ambiente onde a força e a resistência física, bem como a submissão ao patrão, fazem a diferença entre a vida e a morte, entre ter o que comer e morrer de fome. É na convivência com seus companheiros de infortúnio que o emigrante aprenderá o valor da solidariedade e reconhecerá a condição humana de individuos que antes ele desprezaria.

No seringal, Alberto era apenas mais um trabalhador, e é a esses trabalhadores, condenados a percorrer um círculo sem saída, que Ferreira de Castro dedica $A$ selva. É um cearense desiludido, não mais o tipo alegre como o registrado por Euclides da Cunha em sua correspondência, quem dará as lições de sobrevivência ao "brabo" [novato na extração do látex] português. Sobrevivência que não dependia apenas de escapar dos perigos naturais, mas de aprender as regras de sua nova condição de "sujeito" sem direitos. 


\section{Terra fria}

Se em Emigrantes e A selva, Ferreira de Castro focaliza a vida do emigrante português no exílio, em Terra fria pouco ficamos sabendo dos anos que Santiago passou na Califórnia. E o pouco informado, bem como a construção do personagem, não permitem ilusões sobre o caráter do "filho da Rita", sugerindo que Santiago usou de todos os meios para enriquecer. Terra Fria, na verdade, não é a história de Santiago, pois o romance focaliza em detalhes muito mais cuidadosos a vida do casal Leonardo e Ermelinda, o modo de vida dos moradores da aldeia barrosã de Lordelo e os efeitos da chegada de Santiago sobre a vida de todos eles.

Em Terra fria não temos o retorno de um "brasileiro", mas de um "americano". A alcunha recebida por Santiago refere-se ao seu destino de emigrante, os Estados Unidos da América, não a uma diferença qualitativa em relação aos portugueses que voltaram do Brasil. Um tópico comum às histórias de "brasileiros" está ostensivamente presente no romance, a casa do novo rico. A construção de uma grande residência é o primeiro sinal de que Santiago está para retornar. E em uma terra monótona, de gente apegada a tradições seculares, a expectativa da volta do conterrâneo domina todas as conversas. A chegada do arredio personagem modifica a vida de todos. Desconfiado, pouco disposto a confraternizações e com ares de superioridade, Santiago não se adapta à vida local, antes a perturba e transforma.

O dissimulado e manipulador Santiago, com o auxílio de sua mãe, seduz as jovens contratadas para o serviço doméstico da residência, descartando-as quando engravidam. Acaba assassinado pela enciumada Ermelinda, cujo marido, Leonardo, assume o crime para proteger a esposa e o filho que acredita ser seu.

A prisão de Leonardo e a confissão de Ermelinda são o desfecho do drama. Em um salto temporal, encontramos Leonardo vivendo na 
Espanha e casado com a filha de seu antigo patrão. Quanto a Ermelinda, tem ainda algum tempo de condenação a cumprir.

Leonardo é incapaz de perceber o que se passava com sua esposa, como ela se transformou depois de contratada para trabalhar para o “americano". Em seus repetitivos monólogos percebemos que só há espaço em seu pensamento para o melhor modo de ganhar dinheiro. Como nas piores anedotas, ele é o último a saber que foi traído. Quase como compensação por sua parvoíce ele termina o romance casado com a filha de seu antigo patrão e usufruindo da riqueza conseguida pelo outro.

A transformação de Ermelinda, no entanto, acaba por parecer um tanto brusca. Com certa rapidez, a esposa dedicada e compreensiva do início do romance deixa-se seduzir pelo patrão, convence o marido da importância de ter um filho, já concebido com o amante, e silencia quando o esposo assume o assassinato de Santiago. Pode-se argumentar que tal transformação demonstra, intensamente, o poder de Santiago sobre ela, o que justificaria o apagamento de suas características iniciais, que incluíam a preocupação de não se sujeitar a humilhações e de não deixar que o marido se sujeitasse.

A caracterização de Santiago centra-se nos aspectos negativos do “americano". O personagem age apenas de modo egoísta. Todos os seus gestos têm objetivos claros, manter distantes os vizinhos, conseguir da mãe o auxílio para seus projetos de sedução, conseguir das empregadas os favores sexuais.

\section{Convergências}

Nos três romances destacamos alguns temas recorrentes: o “brasileiro", a pobreza, a emigração, a exploração da miséria, a ambição.

Emigrantes é o romance que contempla maior quantidade desses elementos, focalizando e revelando detalhes do processo social e econômico que é a emigração. A selva, por sua vez, suprime detalhes da partida de Alberto, cujo retorno a Portugal também não entra na 
história, mas há a indicação de que o homem que voltaria ao país assumiria como missão atuar na busca por um sistema mais justo. Assim como Alberto, Manuel é um personagem mais bem elaborado em sua complexidade do que aqueles que encontramos em Terra fria, o que torna mais crivel sua transformação. É possivel identificar nos dois uma incapacidade inicial de perceber e entender o mundo que os cerca. Incapacidade mais grave, é claro, quando sabemos que Alberto era um estudante de direito. É o encontro com uma realidade imprevista que dará a ambos uma compreensão mais ampla do mundo. Nos dois casos, a viagem ao Brasil significa para os personagens o fim de uma série de ilusões. Alberto, sem dúvida, voltará um homem melhor, humanizado pela experiência. Quanto a Manuel, se não volta pior no que se refere ao caráter, volta desencantado e vazio de sonhos.

O personagem que encarna a figura do aproveitador incapaz de um único gesto nobre é comum aos três romances. Feio e gordo, o Macedo de A selva, ainda que lhe faltem os joanetes, seria um "digno" representante dos "brasileiros" do Romantismo. O tio de Alberto não hesita em livrar-se das despesas com o sobrinho convencendo-o a transferir-se para um seringal, mesmo sabendo das dificuldades do trabalho, da escravização pelas dividas e dos perigos na floresta. O comportamento do personagem e as informações sobre ele não deixam dúvidas quanto ao caráter de Macedo:

[...] a riqueza se apresentava de fácil posse, desde que a audácia se antepusesse aos escrúpulos. [...] Fora assim que o tio enriquecera e tinha já duas quintas em Portugal". (CASTRO, 1972, p. 41)

Como já se viu, a ausência de escrúpulos é também a fórmula do sucesso de Nunes em Emigrantes. E o que se diz da origem da fortuna de Santiago não é nada lisonjeiro:

Do caráter de Santiago pouco se sabia também, tão diferente se apresentava do que era antes de emigrar. Correra que ele não se portara bem com a mulher, filha de açorianos que viviam na América. Ter-lhe-ia dado tantos desgostos e maus tratos que ela morrera sem pena do mundo e, logo que a vira na cova, andara 
às turras com sogros e cunhados, para se apropriar de tudo quanto à falecida pertencia e que, ainda assim era muito. (CASTRO, 1980, p. 41)

Santiago não é feio e nem glutão, mas os sentimentos sórdidos manifestam-se na atitude soberba e no comportamento lascivo do "americano":

A solidão que a si próprio impunha e nervos e sangue ainda em vigor faziam-lhe luzir os olhos perante toda a mulher que tivesse palmo de cara apetecivel. Mas, aos seus quarenta e quatro anos saudáveis só satisfazia, totalmente, carniça ainda não endurecida, frangotas novas, delgaditas se fosse possivel, que, não sendo, também serviam as alentadas, conquanto não tivessem chegado aos trinta.

Nos primeiros dias fora dificil harmonizar o respeito que queria em seu redor com o que precisava para encher quanto nele estava vazio.(CASTRO, 1980, p. 53)

Se nas histórias analisadas a riqueza aparece, com frequência, associada à falta de vergonha e ao desprezo pelos outros, voltar derrotado da América envergonha os que retornam. O sentimento de vergonha e humilhação é partilhado por Manuel da Bouça Emigrantes - e pelo amigo de Leonardo em Terra fria:

Artur Lopes vacilou, um momento. Depois, com monossílabos confessou. Não, não tinha arranjado coisa que se visse. Trabucara quanto pudera, mas não arranjara nada de jeito. Hoje, estava mau por toda parte. Trouxera umas notas, muito poucas, mas não dava para nada. (CASTRO, p. 246-247)

Retornar não significa retomar a vida de outrora. Os que obtêm êxito querem parecer diferentes, melhores, superiores; os que falharam querem se esconder. $O$ que se percebe nos personagens citados é que quase todos manifestam um estranhamento com relação ao ponto de origem. Os fios partidos dificilmente se reatam e deixa de haver o que constitui uma identidade local. Eles não partilham com os que ficaram os momentos idênticos, as histórias semelhantes, a vida da comunidade; fazem parte de outras histórias. Na terra de origem são motivo de curiosidade, de estranhamento, apontados como vencedores ou perdedores. No Brasil, alguns eram chamados de "marinheiros", em 
Portugal são chamados de "brasileiros", de qualquer forma são indivíduos que se sentem diferentes e como tal são percebidos e recebidos. Nem todos tiveram uma "mísera sorte", mas a emigração, a vida do outro lado, faz com que eles partilhem uma "estranha condição". A cada um deles poder-se-ia perguntar: valeu a pena?

\section{Referências bibliográficas}

CASTRO, Ferreira de. Emigrantes. In: Obra completa v. 2. Rio de Janeiro: José Aguilar, v. 3(Biblioteca Luso-Brasileira. Série Portuguesa), 1959. . A selva. São Paulo: Verbo, 1972. Terra fria. 12. ed. Lisboa : Guimarães \& Ca., Editores, 1980. QUEIRÓS, Eça de. "Carta-prefácio." In: MAGALHÃES, Luís de. O brasileiro Soares. Lisboa: Imprensa Nacional-Casa da Moeda, s.d. 